\title{
Nearly complete TME quality conundrum
}

\author{
A. Dyatlov ${ }^{1} \cdot$ M. Gachabayov ${ }^{1} \cdot$ R. Bergamaschi ${ }^{1}$
}

Received: 21 November 2017 / Accepted: 23 November 2017 / Published online: 13 December 2017

(c) Springer International Publishing AG, part of Springer Nature 2017

\section{Dear Sir,}

In their systematic review and meta-analysis of 11 randomized controlled trials (RCT), Pedziwiatr et al. [1] concluded that there was no difference in oncological outcomes between laparoscopic and open proctectomy for rectal cancer. Previous enthusiasm for a laparoscopic approach has been recently counterbalanced by the increased rates of circumferential resection margin involvement secondary to the impaired ergonomics of non-articulating laparoscopic instruments in the confined space of the pelvis [2].

In their review, Pedziwiatr et al. provided (1) no data from 1966 to 2005 ; (2) no data on tumor distance from the anal verge; (3) no data on the quality of total mesorectal excision (TME) for 6 of 11 RCTs; (4) no emphasis on the non-inferiority design of the RCTs utilizing intent-to-treat analysis.

In a recent meta-analysis, Martinez-Perez et al. [3] reported that laparoscopic proctectomy for rectal cancer was inferior to its open counterpart in terms of TME quality. Martinez-Perez et al. [3] drew such conclusions analyzing nearly complete together with incomplete TME quality specimens as compared to complete. Conversely, Pedziwiatr et al. [1] analyzed nearly complete with complete TME quality and compared them to incomplete cases. It is our opinion that the nearly complete resected specimens in Nagtegaal et al.'s [4] three-tiered classification were not intended to be considered as complete TME quality.

\section{Compliance with ethical standards}

Conflict of interest The authors declare that they have no conflict of interest.

Ethical approval This article does not contain any studies with human participants performed by any of the authors.

Informed consent Informed consent is not applicable as this is a correspondence paper.

\section{References}

1. Pedziwiatr M, Malczak P, Mizera M et al (2017) There is no difference in outcome between laparoscopic and open surgery for rectal cancer: a systematic review and meta-analysis on short- and long-term oncologic outcomes. Tech Coloproctol 21:595-604

2. Abbas SK, Yelika SB, You K et al (2017) Rectal cancer should not be resected laparoscopically: the rationale and the data. Tech Coloproctol 21:237-240

3. Martinez-Perez A, Carra MC, Brunetti F, de Angelis N (2017) Pathologic outcomes of laparoscopic vs open mesorectal excision for rectal cancer: a systematic review and meta-analysis. JAMA Surg 152(4):e165665

4. Nagtegaal ID, Cornelis JH, van de Velde CJ et al (2002) Macroscopic evaluation of rectal cancer resection specimen: clinical significance of the pathologist in quality control. J Clin Oncol 20:1729-1734
R. Bergamaschi

rcmbergamaschi@gmail.com

1 Division of Colorectal Surgery, Westchester Medical Center, New York Medical College, Taylor Pavilion, Suite D-365, 100 Woods Road, Valhalla, NY 10595, USA 